\title{
Creation and Validation of a New Personal Resilience Scale
}

\author{
Wei Wei ${ }^{1}$ and Robert J. Taormina ${ }^{1}$ \\ ${ }^{1}$ University of Macau
}

\begin{abstract}
This study assessed the validity and reliability of a newly created personal resilience measure with four subscales, i.e., Determination, Endurance, Adaptability, and Recuperability. Convergent validity was tested with Chinese Values and Future Orientation, and divergent validity was tested with Neuroticism. The results showed significant correlations in the expected directions between the four personal resilience domains and each test variable. Concurrent validity used the "Known-Groups" method, which yielded the expected significantly different mean scores between the high and low groups. The reliabilities of the subscales were also excellent. Thus the validity and reliability of the new personal resilience measure were confirmed.
\end{abstract}

Keywords: Personal Resilience, Chinese Values, Neuroticism, Future Orientation.

\section{Introduction to Resilience}

In psychology, the concept of resilience is used to refer to such characteristics as hardiness [1], invulnerability [2], stress-buffering [3], and stress-related growth [4]. Also, different researchers had different definitions because resilience has been used in many ways in the literature, which resulted in no consensus on how it should be defined. For example, Masten [5] said that resilient people have the ability to overcome stressful conditions, while Luthens et al. [6] said resilience can be developed as a capacity to rebound from adversity. Thus, Luthar et al. [7] thought that the definitions of were still unclear because they were too diverse. Hence, many different types of resilience measures have been developed, but all seem to be measure different things.

This means that a clear definition of personal resilience is still needed. Therefore, in the present research, a more operational definition is used that is based on the most salient underlying concepts derived from the literature. Thus, the definition used here for personal resilience is that it is "a multifaceted construct that includes a person's determination, and ability to endure, adapt, and recuperate from adversity.

\subsection{Need for a New Personal Resilience Measure}

Because of the difficulty that previous research had with providing accurate operational definitions for resilience, different researchers have had different understandings and foci, which resulted in problems with measuring resilience. For example, Kumpfer [8] mentioned that research on resilience had many difficulties creating good measures, and that many variables are needed to determine which are significant or predictive of positive results. Friborg et al. [9] indicated that "A clear-cut taxonomy, as well as measurement instruments for studying the construct is, however, still lacking” (p. 29).

Therefore, whereas there has been no standard concept of resilience and the measures of resilience had different emphases, there has been no generally accepted scale to measure resilience. For example, Connor and Davidson [10] created a 25-item measure (CD-RISC) which found five subscales to measure resilience. But Campbell-Sill and Stein [11] argued that the CD-RISC measure is unstable in two of its factors. In another attempt, Friborg et al. [12] created a resilience scale for adults (RSA), which contains 37 items that revealed six factors of resilience. But Ahern et al. [13] showed that the RSA scales had suspicious validity and generalizability because they used a non-random sample, and had a low response rate.

Thus, early attempts to measure resilience found multiple factors even though most theories did not suggest that resilience had many parts, and, therefore, most scales were not created at the outset to empirically measure multiple facets. Nonetheless, Ungar [14] stated that resilience should be studied as a multidimensional construct. For these reasons, in the present research, a new measure for resilience was created, not as a single factor, but, rather, the new resilience measure contains four critical domains, each with its own set of items, to constitute a multifaceted, 4-dimensional resilience scale.

\subsection{Creation of the New Measure for Resilience}

This paper argues that resilience is a multifaceted construct because several aspects of resilience can be found in the literature. That is, the literature on personal resilience provided the theoretical basis from which the items were developed. These included some specific characteristics, such as willpower [15], durability [16], flexibility [17], and especially the ability to come back after experiencing hardship [18]. Therefore, the new measure was created to contain four domains to more comprehensively measure resilience, and each domain includes several items to measure each facet. 
The four domains were given the following names: (1) Determination (2) Endurance, (3) Adaptability, and (4) Recuperability. Whereas the four domains were based on the components that were identified in much of the literature on resilience, they focus on the critical aspects of the resilience construct.

\section{Validity of the Personal Resilience Measure}

As this was a new measure, its four facets had to be tested for their validity, which was established in several ways. One was through content validity, i.e., the items were created from the theoretical literature. A second was convergent validity, which assesses its relationship with conceptually related measures, in this case, Chinese Values and Future Orientation. A third was by divergent validity, i.e., to assess its relation with a characteristic that is antithetical to being resilient, in this case, Neuroticism. And a fourth way was through concurrent validity, which is by the "known groups" method, i.e., where the scores on the resilience measure of groups of people who are known to be either high or low on resilience are compared to each other.

\subsection{Content Validity}

Content validity was established by virtue of the items being created from the theoretical conceptions in the published literature [10], [12], [19]. Although much has been written about helping people overcome hardships, those approaches were based on external factors such as social support. The approach used in this paper focused on resilience as an internal characteristic, which can exist at different levels in different people; similar to what is found with any other personality characteristic.

\subsection{Convergent Validity}

Convergent validity was tested by comparing the resilience scores with two conceptually related measures. One was the Chinese Values measure, which assesses adherence to principles such as "perseverance" that relates to the resilience aspect of determination. The other was Future Orientation, which also relates to the resilience aspect of determination because this implies that the person wants to obtain something in the future.

\subsection{Divergent Validity}

Divergent validity was tested by comparing the resilience scores with a Neuroticism measure that was deemed antithetical. As Neuroticism is characterized by feelings of worry and anxiety, it is generally a defeatist attitude, which is the reverse of resilient determination.

\subsection{Concurrent Validity}

Concurrent validity refers to the ability of a measure to distinguish between people already known to differ on some characteristic. That is, a measure of a construct is valid when people with high levels of that trait score high on the measure, and people with low levels of that trait score low. People of each type were tested.

\section{Method}

The purpose of this study was to test the validities of the facets of the new Personal Resilience Measure. In addition, three measures that were thought to have some relation to the resilience construct were included, i.e., Neuroticism, Chinese Values, and Future Orientation. Neuroticism was included because it is a defeatist attitude that should be negatively related to resilience. The Chinese values measure was included because the values represent ideas that are consistent with certain aspects of being resilient (e.g., endurance). Also, Future Orientation was assessed because a resilient person would likely be concerned about the future in order to have a reason to keep coming back despite setbacks.

\subsection{Respondents}

There was a total of 70 respondents overall, who were all Chinese adults ranging in age from 20 to 56 years $(\mathrm{M}=34.31, \mathrm{SD}=8.90)$. For Education, 4 finished primary school, 31 secondary school, 32 had a bachelor's degree, and 3 had a master's degree or higher. For Marital Status, 21 were single, 42 married, and 7 indicated "other" (divorced, separated, or widowed). For monthly income (RMB), 14 earned less than 1,000, 22 earned 1,000-2,999, 18 earned 3,000-4,999, 10 earned 5,000-6,999, and 6 earned 7,000-8,999.

Based on the literature that defined resilience, two groups of people were identified. The high resilience group was hospital medical workers who were frequently exposed to many types of disease and illness but who have endured and been successful. The low resilience group was a set of individuals who have not endeavored to establish a career, have accepted being unemployed, and given up on trying to find work. Thus, for the two groups that were compared, there were 35 (16 male, 19 female) in the high resilience group and 35 (17 male, 18 female) in the low resilience group.

\subsection{Measures}

Personal Resilience. This was measured with a newly created scale, which had four 10-item subscales, namely, Determination, e.g., "My character is one of great determination"; Endurance, e.g., "I can live with any difficulties that I have to face"; Adaptability, e.g., "I can find different ways to do things"; and Recuperability, e.g., "I will come back in spite of adversity." The reliabilities of these scales are discussed in the Results.

Neuroticism. To measure Neuroticism, an 8-item scale that focused on the "worry" aspect of Neuroticism was used. Five items came from the Neuroticism facet of the NEO Personality Inventory (NEO-PI-R, [20]), 
e.g., "I often worry about things," and three items from Peterson and Seligman's [21] Neuroticism measure, e.g., "I usually expect the worst." The items were selected from two scales because each original scale had multiple facets, so the eight items were chosen because they appeared to best represent the central concept.

Chinese Values. This variable was measured with Taormina's [22] 12-item Chinese Values scale. Sample items are "Respect for tradition" and "Having ordered relationships." Respondents were asked "To what extent do you personally live your life by these values?" and the responses were measured on a 5-point scale ranging from 1 (never) to 5 (always).

Future Orientation. As there was no suitable measure for this variable, it was measured with a newly created 7-item scale. Sample item is "Things work out better if I plan them in advance." Items for the full scale can be obtained from the authors.

\subsection{Procedure}

With permission from the head of the Kunming army hospital, the data for the high resilience group were collected from 35 hospital medical workers who were expected to have high levels of resilience because of their frequent exposure to illness and trauma, and yet survived without becoming seriously ill themselves.

As low resistance individuals tend to succumb to difficulties and give up in the face of adversity, they are not usually found in existing groups. But in some rural villages many people are long-time unemployed, have given up looking for work and lost the motivation to improve their lives, and one village leader introduced the researcher to these villagers. Thus, 35 long-time unemployed represent the low resilience group.

All data were obtained following the guidelines of the American Psychological Association. The researcher explained the purpose of the study to the potential participants and asked if they were willing to participate. Those who agreed were given a questionnaire, which took about 15 minutes to complete, and which were collected on site, Of the 70 people asked, all completed the questionnaires, yielding a response rate of $100 \%$.

\section{Results}

In this section, the results are reported in several parts. First, the validity results are explained. For these, the convergent, divergent, and concurrent validities are shown (note that there is no direct statistical test for the content validity, which was explained in Section 2). Next the reliability results are shown.

\subsection{Convergent Validity}

The correlations between the Personal Resilience measures and Chinese Values were all positive and highly significant (all p-values $<.001$ ), indicating strong convergent validity. Likewise, all correlations between the Personal Resilience measures and Future Orientation were also positive and highly significant (all p-values $<.001$ ), further indicating excellent convergent validity. These results are shown in Table 1.

\subsection{Divergent Validity}

For divergent validity of the new measures, all the correlations between the Personal Resilience measures and the Neuroticism scale were all negative and highly significant (all p-values < .001), indicating strong divergent validity of the new scales. See Table 1.

\subsection{Concurrent Validity}

The concurrent validity was assessed by t-tests that compared the means of the two groups (i.e., hospital workers was the high group, and people who gave up seeking work were the low group) that were known to be different on personal resilience.

On all four of the new resilience scale dimensions, namely, Determination, Endurance, Adaptability, and Recuperability, the high group always scored higher than the low group, as expected, with highly significant t-test results, all p-values $<.001$. Thus, the t-test results strongly supported the concurrent validity for the new personal resilience scale. These detailed results of the t-tests are shown in Table 2.

Table 1. Means, Standard Deviations, and correlations among the variables $(\mathrm{N}=70)$.

\begin{tabular}{|c|c|c|c|c|c|c|}
\hline & Mean & SD & 1 & 2 & 3 & 4 \\
\hline 1. Determination & 3.72 & 0.71 & $(.94)$ & & & \\
\hline 2. Endurance & 3.77 & 0.76 & $.88^{* * * * *}$ & $(.95)$ & & \\
\hline 3. Adaptability & 3.78 & 0.70 & $.89^{* * * * *}$ & $.91^{* * * * *}$ & $(.94)$ & \\
\hline 4. Recuperability & 3.76 & 0.75 & $.89^{* * * * *}$ & $.91^{* * * *}$ & $.90^{* * * * *}$ & $(.94)$ \\
\hline 5. Neuroticism & 2.81 & 0.76 & $-.77^{* * * *}$ & $-.77^{* * * *}$ & $-.78^{\text {****** }}$ & $-.81^{* * * *}$ \\
\hline 6. Chinese Values & 4.17 & 0.45 & $.45^{* * * *}$ & $.47^{* * * *}$ & $.43^{* * * *}$ & $.53^{* * * *}$ \\
\hline 7. Future Orientation & 3.39 & 0.66 & $.79^{* * * *}$ & $.80^{* * * *}$ & $.83^{* * * * *}$ & $.81^{* * * * *}$ \\
\hline
\end{tabular}

Note. All variable values ranged from 1 (low) to 5 (high). Reliabilities are in the parentheses ( ) along the diagonal.

${ }^{* * * *}$ All correlations were significant at the $\mathrm{p}<.001$ level. 
Table 2. Mean Score comparisons (t-tests) between the High and Low Resilience groups $(\mathrm{N}=70)$.

\begin{tabular}{|c|c|c|c|c|}
\hline & $\begin{array}{c}\text { High Resilience } \\
\quad(\mathrm{N}=35)\end{array}$ & $\begin{array}{c}\text { Low Resilience } \\
(\mathrm{N}=35)\end{array}$ & $\mathrm{t}(68)$ & $p$ \\
\hline Determination & $\begin{array}{c}4.36 \\
(S D=0.32)\end{array}$ & $\begin{array}{c}3.07 \\
(S D=0.23)\end{array}$ & 19.07 & $<.001$ \\
\hline Endurance & $\begin{array}{c}4.46 \\
(S D=0.30)\end{array}$ & $\begin{array}{c}3.07 \\
(S D=0.28)\end{array}$ & 20.05 & $<.001$ \\
\hline Adaptability & $\begin{array}{c}4.43 \\
(S D=0.28)\end{array}$ & $\begin{array}{c}3.13 \\
(S D=0.23)\end{array}$ & 20.96 & $<.001$ \\
\hline Recuperability & $\begin{array}{c}4.46 \\
(S D=0.25)\end{array}$ & $\begin{array}{c}3.05 \\
(S D=0.25)\end{array}$ & 23.86 & $<.001$ \\
\hline
\end{tabular}

\subsection{Reliability of the New Personal Resilience Scales}

For each of the four new 10-item subscales of the Personal Resilience measure, a separate Cronbach alpha (internal consistency) reliability was computed. These were: .94 for Determination; .95 for Endurance; .94 for Adaptability; and .94 for Recuperability. All of the reliability values had excellent internal consistencies, i.e., they were well above the recommended value of .70 [23].

\section{Discussion}

The main purpose of this study was to test the validity and reliability of a newly created, 4-part personal resilience scale.

This study also reported on four types of validity, i.e., the content, convergent, divergent, and concurrent validity, of the new resilience measure. For the content validity, based on an extensive literature review, the items for the new scale were drawn from a number of published theories, which provided sound theoretical foundations for the four personal resilience subscales.

For convergent validity, all the personal resilience subscales were strongly and positively related to the Chinese Values and Future Orientation scales. Regarding Chinese Values, which have a long tradition in China, traditional cultures have been considered to advocate personal characteristics such as being adaptive and enduring [24], that are naturally related to personal resilience. Additionally, regarding Future Orientation, some authors considered that having a future purpose in life can help people to endure hardships [25]. Therefore, logically, resilient people have a cognitive determination to complete their goals. Thus, the similar results found in this study strongly supported the convergent validity of the new resilience measure.

For divergent validity, this test examined a personal characteristic that was considered antithetical to being resilient, i.e., neurotic people tend to be anxious about the future rather than to set themselves to determinedly plan for the future. In fact, previous resilience studies have shown significant negative relationships between neuroticism and resilience [26]. And this study found the same result, i.e., strong significant negative correlations between all the new personal resilience subscales and the Neuroticism measure. Thus, the divergent validity of the new scale was strongly supported.

For the concurrent validity, the "known-groups" test was used. The "high resilience" group was composed of hospital workers who had to endure exposure to illness and disease, and yet succeeded over long periods of time because of their determination to succeed; while the "low resilience" group included long-term unemployed people who had little or no motivation to improve their life condition. The results demonstrated a strong difference between the two groups, with the high resilience group (hospital workers) scoring significantly higher than the low resilience group (the long-term unemployed) on all four personal resilience subscales. This confirmed that the new measure accurately reflects the resilience facets, thus supporting the concurrent validity of the new resilience measure.

Regarding the reliability, the high Cronbach alpha reliability scores found for each of the four domains, namely, Determination, Endurance, Adaptability, and Recuperability, indicated excellent internal consistencies, ranging from .94 to .95 .

\section{Conclusion}

In conclusion, this study provided encouraging empirical support for the reliability and validity of the new personal resilience scale created here, namely, the Wei and Taormina Personal Resilience Scale (WT-PRS). The excellent psychometric properties also suggest that the new scale could be usefully applied in both academic and practical settings.

This study also addressed several gaps in the resilience literature. First, by operationalizing the resilience definition, the need for the concept to be made clearer [7] was answered. Another need that was addressed was to have a usable, multi-faceted instrument [9] for measuring resilience, which this new scale provides. Furthermore, the need for a measure to examine resilience in relation to other factors [8] was also answered because the new measure contains viable subscales for that purpose. Thus, personal resilience can now be more effectively studied in future research areas, 
such as the applied area of organization behavior.

\section{References}

[1] S. Kobasa, "Stressful life events, personality \& health: An inquiry into hardiness," Journal of Personality and Social Psychology, 37(1), pp. 1-11, 1979

[2] E. Anthony, and B.J. Cohler, "The invulnerable child," New York: Guilford, 1987.

[3] R.J. Haggerty, L. Sherrod, N. Garmezy, and M. Rutter, "Stress, risk, and resilience in children and adolescents: Processes, mechanisms, interventions," New York: Cambridge University Press, 1996.

[4] C.M. Aldwin, "Stress, Coping and Development (2nd ed.)," London: Guilford Press, 2007.

[5] A.S. Masten, "Ordinary magic: Resilience processes in development," American Psychologist, 56(3), pp. 227-238, 2001.

[6] F. Luthans, G.R. Vogelgesang, and P.B. Lester, "Developing the psychological capital of resiliency," Human Resource Development Review, 5(1), pp. 25-44, 2006.

[7] S.S. Luthar, D. Cicchetti, and B. Becker, "The construct of resilience: A critical evaluation and guidelines for future work," Child Development, 71(3), pp. 543-562, 2000.

[8] K.L. Kumpfer, "actors and processes contributing to resilience: The resilience framework," In M. D. Glantz, J. L. Johnson (Eds.), "Resilience and development: Positive life adaptations," Dordrecht Netherlands: Kluwer Academic Publishers, pp. 179-224, 1999.

[9] O. Friborg, D. Barlaug, M. Martinussen, J.H. Rosenvinge, and $\mathrm{O}$. Hjemdel, "Resilience in relation to personality and intelligence," International Journal of Methods in Psychiatric Research, 14(1), pp. 29-42, 2005.

[10] K.M. Connor, and J.R.T. Davidson, "Development of a new resilience scale: The Connor-Davidson Resilience Scale (CD-RISC)," Depression and Anxiety, 18(2), pp. 76-82, 2003.

[11] L. Campbell-Sills, and M.B. Stein, "Psychometric analysis and refinement of the Connor-Davidson Resilience Scale (CD-RISC): Validation of a 10-item measure of resilience," Journal of Traumatic Stress, 20(6), pp. 1019-1028, 2007.

[12] O. Friborg, O. Hjemdel, J.H. Rosenvinge, and M. Martinussen, "A new rating scale for adult resilience: What are the central protective resources behind healthy adjustment?" International Journal of Methods in Psychiatric Research, 12(2), pp. 65-76,
2003.

[13] N.R. Ahern, E.M. Kiehl, M. Sole, and J. Byers, "A review of instruments measuring resilience," Issues in Comprehensive Pediatric Nursing, 29(2), pp. 103-125, 2006.

[14] M. Ungar, "Resilience across cultures," British Journal of Social Work, 38(2), pp. 218-235, 2008.

[15] C.M. Youssef, and F. Luthans, "Positive organizational behavior in the workplace: The impact of hope, optimism, and resilience," Journal of Management, 33(5), pp. 774-800, 2007.

[16] M. Rutter, "Resilience in the face of adversity: Protective factors and resistance to psychiatric disorder," The British Journal of Psychiatry: the journal of mental science, 147, pp. 598-611, 1985.

[17] C.B. Lam, and C.A. McBride-Chang, "Resilience in young adulthood: The moderating influences of gender-related personality traits and coping flexibility," Sex Roles, 56(3-4), pp. 159-172, 2007.

[18] B. Bernard, "Fostering resilience in children," ERIC Digest. Urbana, IL: University of Illinois, 1995.

[19] G.M. Wagnild, H.M. Young, "Development and psychometric evaluation of the Resilience Scale," urnal of Nursing Measurement, 1(2), pp. 165-178, 1993.

[20] P.T.Jr. Costa, and R.R. McCrae, "NEO-PI-R Professional Manual," Odessa, FL: Psychological Assessment Resources, 1992.

[21] C. Peterson, and M.E.P Seligman, "Character strengths and virtues: A classification and handbook," New York: Oxford University Press, 2004

[22] R.J. Taormina, "Social and personality correlates of gambling attitudes and behavior among Chinese residents of Macau," Journal of Social and Personal Relationship, 26(8), pp. 1047-1071, 2009.

[23] J.C. Nunnally, "Psychometric theory," New York: McGraw-Hill, 1978.

[24] J.Z. Li, and Y.P. Liang, "Contemporary interpretation of Confucius educational ideas," Theory and Practice of Education, 28(12), pp. 12-14, 2008.

[25] V.E. Franke, "Man's search for meaning: An introduction lo logotherapy," Boston: Beacon Press, 1959.

[26] A. Furnham, J. Crump, and J. Whelan, "Validating the NEO personality inventory using assessor's ratings," Pers Individual Diff, 22(5), pp. 669-75, 1997. 